DOI: $10.17805 /$ zpu.2017.2.17

\title{
Теоретический подход к измерению актуальной мотивации социальной группы *
}

\author{
П. А. КОРОТКОВ \\ ПОВОЛЖСКИЙ ГОСУДАРСТВЕННЫЙ ТЕХНОЛОГИЧЕСКИЙ УНИВЕРСИТЕТ
}

В статье представлен авторский подход к измерению актуальной мотивации повседневной жизни социальной группы. Подход направлен на решение задачи переноса результатов лабораторных исследований актуальной мотивации на большие социальные группы. На основе междисциплинарного подхода уточняются понятия актуальной мотивации повседневной жизни и трудности задачи с привлечением теории интенсивности мотивации, теории деятельности, исследований бюджетов времени, баланса работы и жизни, сравнительно-физиологических исследований функциональной организации целостного поведенческого акта.

Обосновывается выбор средней продолжительности рабочего времени в качестве референта трудности задачи с одновременным уточнением объекта исследования. Объект исследования конкретизируется как работающие по найму в капиталистических странах в условиях относительно стабильной общественной ситуации. Выбор объекта исследования обусловлен тем, что работающие по найму - это самая многочисленная группа в доминирующем типе общества, определяющая тенденции его развития. Переход на уровень стран продиктован стремлением избежать «экологической ошибки», возникающей при агрегировании данных индивидуального уровня. Обосновывается возможность использования уровня распространенности самоубийств, взятого с обратным знаком, в качестве социального коррелята актуальной мотивации повседневной жизни работающих по найму.

Разработана теоретическая модель балльной оценки актуальной мотивации повседневной жизни работающих по найму на основе анализа предполагаемой нелинейной (квадратичной) зависимости уровня распространенности самоубийств от средней продолжительности рабочего времени с использованием панельной регрессии с фиксированными эффектами, позволяющей учесть влияние переменных социально-экономического развития и других неучтенных факторов, оставив для анализа только фактор «трудность задачи».

Ключевые слова: повседневная жизнь, работающие по найму, актуальная мотивация, трудность задачи, рабочее время, самоубийство

\section{ВВЕАЕНИЕ}

$\mathrm{B}$ связи с тем что мотивация является междисциплинарным многоаспектным конструктом, не наблюдаемым и не регистрируемым напрямую, возникает проблема ее измерения. Аанная проблема находится в русле современных количественных исследований психологического потенциала больших социальных общностей, мобилизуемого не только в экстремальных, но и в самых обычных, нормальных условиях (Журавлев, 2009: Электронный ресурс).

В социологии мотивация повседневной деятельности изучается в рамках проблемы повседневности (Караханова, Бессокирная, Большакова, 2014, 2015) и представляет собой общий конструкт, не имеющий собственного определения, который включает

* Исследование выполнено при финансовой поддержке РФФИ в рамках научного проекта «Метод измерения актуальной мотивации повседневной жизни работающих по найму», грант № 16-36-00187 мол_а.

The study was financially supported by RFBR, research project "The Method of Measuring the Actual Motivation of the Employees' Daily Life”, grant No. 16-36-00187 mol_a. 
мотивацию труда, мотивацию бытовой деятельности и мотивацию использования свободного времени (Караханова, Бессокирная, Большакова, 2015).

В психологии мотивация кратко определяется как процесс, детерминирующий направление и энергизацию поведения (Elliot, 2006). При этом первый аспект «что субъект делает»- изучен значительно лучше, чем второй (актуальная мотивация) - «сколько усилий субъект прилагает для осуществления инструментального поведения».

Аля количественной оценки (измерения) актуальной мотивации повседневной жизни социальной группы в условиях относительно стабильной общественной ситуации необходимо перенести теоретические обобщения результатов лабораторных исследований актуальной мотивации на уровне индивида и малой группы (Touré-Tillery, Fishbach, 2014; Коротков, Загайнова, 2015) на повседневную жизнь.

Сложность заключается в том, что в повседневной реальности на уровне социальной группы теоретические представления об актуальной мотивации и ее факторах оказываются трудно интерпретируемыми и операционализируемыми даже в косвенных показателях. При этом для корректного использования косвенных показателей требуется разработка новых теоретических подходов с привлечением современных статистических методов.

Предлагается разработать теоретическую модель оценки актуальной мотивации повседневной жизни на уровне социальной группы (работающих по найму), отличающуюся использованием показателей национальной статистики «средняя продолжительность рабочего времени» и «уровень распространенности самоубийств» (взятый с обратным знаком) в качестве эмпирического индикатора фактора актуальной мотивации «трудность задачи» и социального коррелята актуальной мотивации.

Объект исследования - социальная группа (работающие по найму) в капиталистических странах в условиях относительно стабильной общественной ситуации. Предмет исследования - подходы к измерению актуальной мотивации повседневной жизни социальной группы (работающих по найму) в капиталистических странах в условиях относительно стабильной общественной ситуации. Задачи исследования: уточнить основные понятия исследования; обосновать эмпирическую интерпретацию основных понятий; предложить теоретическую модель оценки актуальной мотивации повседневной жизни социальной группы.

\section{ТЕОРЕТИЧЕСКИЕ ОСНОВАНИЯ}

Повседневная жизнь (повседневная деятельность, повседневная реальность, повседневность) является предметом изучения философии, социологии, психологии, культурологии и других наук. В социологии повседневная жизнь может быть определена как привычные, повторяющиеся формы жизнедеятельности, когда происходит реализация обыденных (насущных) материальных и духовных потребностей человека (Российская повседневность ... , 2009). К сферам повседневной жизни относятся труд (работа), быт (семья и быт), досуг (свободное время). При этом основной функцией повседневности выступает жизнеобеспечение (Караханова, Бессокирная, Большакова, 2014). Повседневность исследуется на микро- (личность) и макроуровнях (общество), в статике (уровни и сферы повседневности) и в динамике (трансформации повседневности в условиях изменений в обществе) (Полякова, 2010).

Основным социологическим методом изучения повседневной деятельности, по крайней мере в российской науке, является бюджет времени (Караханова, Бессокир- 
ная, Большакова, 2014, 2015). При этом обследования бюджетов времени, как правило, сочетаются с анализом самооценок мотивации повседневной деятельности. Под мотивацией повседневной деятельности понимается некий общий конструкт, который вкдючает мотивацию труда, мотивацию бытовой деятельности и мотивацию использования свободного времени (Караханова, Бессокирная, Большакова, 2015).

Проблема повседневности также рассматривается в организационной психологии в исследованиях баланса работы и жизни (work-life balance), посвященных анализу соотношений работы и жизни (Guest, 2002; Баханс работы ..., 2016). При этом в отличие от работы (оплачиваемой трудовой деятельности) понятие личной жизни является более размытым: оно либо ограничивается семейной жизнью, либо определяется широко, как все, что не относится к работе: быт, хобби, увлечения, общение с семьей, близкими друзьями, романтические отношения, саморазвитие, здоровье и др.

Большинство подходов связаны с изучением конфликта ( «работа мешает личной жизни», «дичная жизнь мешает работе») или взаимодействия этих двух сфер (Баланс работы ... , 2016). Аавление и требования рабочей сферы отражаются в удлинении рабочего дня, истощении, работе по выходным, оказывая негативное влияние на личную жизнь, оставляя для нее все меньше пространства (Guest, 2002). Качество личной и семейной жизни в целом снижается, в том числе из-за того, что все члены семьи трудоспособного возраста из разных социальных классов заняты оплачиваемым трудом. Социальные последствия включают в себя рост преступности среди несовершеннолетних, злоупотребление наркотиками, снижение участия в общественной жизни, нежелание брать на себя ответственность за заботу о престарелых родственниках и неимущих (там же).

Вместе с тем нехватка или полное отсутствие работы, избыток свободного времени также вызывают неудовлетворенность и переживание дисбаланса жизненных сфер, поскольку работа не только позволяет человеку обеспечить социальный статус и необходимый уровень дохода, но и помогает структурировать время, поддерживать определенный режим дня (Баланс работы ..., 2016).

Актуальная мотивация является предметом изучения теории интенсивности мотивации (Brehm, Self, 1989; Richter, Gendolla, Wright, 2016), развивающей «мотивационный закон трудности» (Хекхаузен, 2003), в основу которой положен «принцип экономии ресурсов (энергии)», в соответствии с которым субъект старается избежать растраты ресурсов. Усилие (мотивационное возбуждение, актуальная мотивация) определяется трудностью инструментального поведения, или трудностью осуществления деятельности, которая направлена на достижение желаемых результатов и (или) избежание неприятных результатов, и операционализируется с использованием показателей сердечно-сосудистой системы, электропроводимости кожи, усилия сжатия рукой (Richter, Gendolla, Wright, 2016).

Теория интенсивности мотивации базируется на предположении о немонотонном (квадратичном) характере связи усилия и воспринимаемой трудности предстоящего или осуществляемого поведения (Gendolla, Wright, Richter, 2012), наблюдаемой при выполнении задачи с заданными стандартами деятельности (определенная трудность задачи), когда субъект может оценить, сколько усилий потребуется для достижения цели. Ао тех пор, пока успех воспринимается достижимым и оправданным, усилие изменяется пропорционально трудности задачи. Если успех воспринимается как невозможный или чрезвычайно труднодостижимый, усилие будет низким. Аругими словами, максимальное усилие прикладывается при таком уровне трудности задачи, 
который, по мнению субъекта, еще является преодолимым; за этим пределом величина усилия резко падает. Аанный предел (максимальное усилие) соответствует потенциальной мотивации, которая, в свою очередь, определяется ценностью (значимостью) цели.

Актуальная мотивация также является предметом физиологических исследований функциональной организации целенаправленного поведения и стремления к достижению цели. Основы проблемы достижения цели были заложены еще И. П. Павловым в 1916 г. в работе «Рефлекс цели», в которой он выдвинул представление о рефлексе цели как о стремлении к обладанию определенным раздражающим предметом, понимая и обладание, и предмет в широком смысле слова, позволяющем анализировать целенаправленное поведение живого организма (Павлов, 1973: 214). В результате теоретического анализа было установлено, что к основным факторам, определяющим плодотворность проявления рефлекса цели, относятся его периодичность и напряжение (существование препятствий на пути к достижению цели). Павлов был убежден, что целые нации различаются по плодотворности проявления рефлекса цели.

Современные физиологи (Кузнецова, Кузьмина, Радченко, 2006; Кузнецова, Горбачева, 2012), продолжая исследования рефлекса цели, выявили общие закономерности достижения цели при изменяющихся физических параметрах (скорость, расстояние, время достижения цели). Так, экспериментально установлено, что снижение скорости приближающегося объекта-цели приводит к снижению мотивации достижения цели вплоть до полного отказа от завершения целенаправленной деятельности (Кузнецова, Горбачева, 2012: 199). Показано, что одним из главных факторов, приводящих к возникновению состояния нервного напряжения, отрицательных эмоций и даже срыву высшей нервной деятельности, является отставление во времени достижения конечного положительного результата деятельности (там же). Собственно, при снижении скорости приближающегося объекта-цели и происходит отставление во времени, которое воспринимается субъектом как показатель трудности задачи.

\section{ОСНОВНЫЕ ПОНЯТИЯ И ИХ ИНТЕРПРЕТАЦИЯ}

Рассматривая в качестве субъекта деятельности социальную группу, уточним основные понятия исследования (цель повседневной жизни, задача повседневной жизни, трудность задачи повседневной жизни, актуальная мотивация повседневной жизни) и их интерпретации, предложенные в наших предыдущих публикациях (Коротков, 2014; Коротков, Загайнова, 2016а).

Цель повседневной жизни социальной группы, исходя из данного определения повседневной жизни и ее основной функции жизнеобеспечения, может быть сформулирована как удовлетворение обыденных (насущных) материальных и духовных потребностей представителей социальной группы, имеющих типичную структуру. При этом реализация данных потребностей происходит главным образом в сферах быта и досуга, т. е. во внерабочее время.

Под задачей в общем случае понимается осуществление целенаправленной деятельности в определенных условиях. Трудовая деятельность представляет собой совокупную деятельность, направленную на удовлетворение обыденных (насущных) материальных и духовных потребностей, т. е. целенаправленную деятельность в повседневной жизни. Отсюда задача повседневной жизни социальной группы определя- 
ется как осуществление трудовой деятельности в условиях относительно стабильной общественной ситуации.

В свою очередь, при увеличении продолжительности трудовой деятельности происходит не что иное, как оставление достижения цели во времени, что воспринимается субъектом как трудность задачи. Отсюда трудность задачи повседневной жизни социальной группы может быть интерпретирована как средняя продолжительность рабочего времени представителей социальной группы. При этом необходимо сделать ряд допущений в контексте теории интенсивности мотивации: во-первых, можно полагать, что задача выполняется в соответствии с заданными стандартами осуществления деятельности, поскольку трудовая деятельность (даже творческая), как правило, регламентируется; во-вторых, люди в среднем выбирают труд, не превышающий их способностей; в-третьих, можно абстрагироваться от характеристик интенсивности и содержания труда, ибо в данном случае не имеет значения, насколько интенсивно человек трудится, отвечает ли работа его интересам: пока рабочее время не истекло, достижение цели повседневной жизни (удовлетворение обыденных потребностей) невозможно.

Таким образом, предлагаемая интерпретация трудности задачи основана на условном противопоставлении работы как преобладающей формы активности и остальной жизни как пространства для реализации подавляющего большинства обыденных (насущных) потребностей. Аействительно, само понятие «баланс работы и жизни» уже содержит противопоставление работы и остальной жизни, или личной и семейной жизни, а наиболее распространенной моделью соотношения работы и жизни, изучаемой в организационной психологии, является конфликтная модель, в которой работа рассматривается как помеха для жизни, и наоборот.

Кроме того, в социологии принято выделять два вида отношения к труду (Здравомыслов, Ядов, 2003): как к средству (внешняя мотивация) и как к цели (внутренняя мотивация). Поскольку актуальная мотивация носит внешний характер, то труд рассматривается как средство жизни (существования), как деятельность, направленная на удовлетворение обыденных (насущных) потребностей, в которой и проявляется актуальная мотивация повседневной жизни.

Условность противопоставления работы и жизни при интерпретации трудности задачи заключается в том, что такая интерпретация не применима в чистом виде, например, для предпринимателей, у которых граница между работой и жизнью размыта, для пенсионеров, для студентов и других групп.

Вместе с тем данная интерпретация вполне применима для наемных работников (работающих по найму) в условиях капитализма. Аействительно, в условиях капиталистического общества происходит отделение труда от своих материальных условий, «отчуждение» основной массы работающих от средств производства (средств и предметов труда), т. е. их превращение в работающих по найму. Объективные условия труда противостоят работающим по найму как чужая собственность, т. е. они могут жить, удовлетворять свои жизненные потребности только при условии, если они будут продавать свою рабочую силу, или отчуждать свой труд (Иеонтьев, 1959, 1975). Поскольку труд является сферой повседневной жизни, то получается, что работающие по найму должны отчуждать важную часть своей жизни. С этой точки зрения труд, безусловно, выступает препятствием для повседневной жизни, ибо «настоящая» жизнь начинается только после прекращения трудовой деятельности. Аругими словами, труд отделяет работающих по найму от достижения цели повседневной жизни. 
Указанные соображения позволяют конкретизировать объект исследования как работающих по найму в капиталистических странах в условиях относительно стабильной общественной ситуации.

Под капиталистическими странами понимаются страны с экономической системой, в которой бо́льшая часть средств производства находится в частной собственности, а производство и распределение происходят под воздействием рыночных механизмов. Переход на уровень стран позволяет избежать «экологической ошибки» в трактовке Инглхарта (Инглхарт, Вельцель, 2011: 334), возникающей при агрегировании данных индивидуального уровня до масштаба больших социальных общностей.

Работающие по найму - это лица, достигшие возраста 15 лет и старше, трудовая деятельность которых осуществляется за оговоренное при найме (при заключении договора с работодателем) вознаграждение (деньги или натура) согласно установленному набору правил, при этом основные фонды, некоторые или все инструменты, помещения, необходимые для выполнения этой деятельности, как правило, не являются их собственностью. Работающие по найму - это самая многочисленная группа (до 60\% населения) в капиталистическом типе общества, определяющая тенденции его развития.

В психологии под актуальной мотивацией понимается текущее усилие, или мобилизованные ресурсы (энергия), необходимое для осуществления целенаправленного поведения. Отсюда актуальная мотивация повседневной жизни работающих по найму может быть определена как типическое (среднее) текущее усилие, прилагаемое работающими по найму для осуществления трудовой деятельности.

Ключ к интерпретации актуальной мотивации повседневной жизни, по-видимому, следует искать еще в теоретических работах И. П. Павлова (И. П. Павлов ... , 1999; Павлов, 1973: 214), в которых показано, что задерживание, торможение рефлекса цели, выражающееся в чувстве бесцельности жизни, является одной из причин самоубийства. С учетом того, что, согласно результатам современных исследований, мотивация играет базисную роль в осуществлении рефлекса цели (Кузнецова, Кузьмина, Радченко, 2006: 197), можно предположить, что падение актуальной мотивации повседневной жизни на уровне индивида должно в конечном счете выражаться в самоубийстве, а на уровне социальной группы - в росте частоты самоубийств.

В самом деле, в предлагаемой интерпретации трудности задачи превышение некоторого предела продолжительности рабочего времени должно приводить к возникновению состояния нервного напряжения, отрицательных эмоций, физического истощения наемного работника, проявляющихся в снижении актуальной мотивации повседневной жизни, вплоть до полного отказа от продолжения трудовой деятельности, и, следовательно, от достижения цели повседневной жизни - удовлетворения обыденных (насущных) потребностей. В свою очередь, отказ от достижения цели повседневной жизни, т.е. отказ от самой жизни, есть самоубийство.

Аанное логическое построение подтверждается на индивидуальном уровне таким явлением как «кароши» (karoshi), обозначающим смерть от переработки, включая самоубийство (Ильин, 2011). Это явление наиболее распространено в Южной Корее при 48-часовой шестидневной рабочей неделе и отпуске, редко превышающем три-пять дней (там же), и в Японии, когда вместо 8 часов в день люди работают по 12-15 часов почти без выходных и часто без отпусков (Тищенко, 2016: Электронный ресурс). Кроме того, постоянно растет число сообщений о случаях «кароши» из Индии, Южной 
Кореи, Тайваня, Китая. Отмечается, что смерть от переработки существует и в странах Европы, в которых это явление пока не получило собственного названия (Gorvett, 2016: Электронный ресурс).

В прессе приводятся, например, следующие фрагменты из предсмертных писем, дневников и блогов «кароши», имеющих переработку от 100 часов в месяц: «Почему все становится таким трудным?» (Президент японской корпорации ..., 2016: Электронный ресурс); «Я не могу ничего делать. Я не хочу ничего делать. Я только чувствую раздражение, опустошение и отвращение» (Fukada, 2012: Электронный ресурс); «У меня всё болит. Мне тяжело. Настроение подавленное. Не могу быстро Авигаться. Помогите» (Гельман, 2015: Электронный ресурс). K примеру, сотрудница сети ресторанов писала своим друзьям перед самоубийством, что никаких чувств, кроме желания выспаться, у нее не осталось, затем она стала признаваться, что видит в смерти облегчение (В Японии женщина совершила самоубийство ..., 2016: Электронный ресурс), а один из наемных работников, выигравших суд у своего работодателя за неоплаченные сверхурочные, признался, что однажды он дошел до точки, где должен был выбрать между жизнью или работой (Fukada, 2012: Электронный ресурс).

По разным оценкам, в Японии ежегодно совершают самоубийство из-за стресса, вызванного переработкой, от 2000 (Президент японской корпорации ..., 2016: Электронный ресурс) до 20000 работников (Факт дня ..., 2016: Электронный ресурс). Отмечается, что чрезмерная переработка особенно распространена среди молодых людей, которые борются за рабочие места с полной занятостью. При этом главной причиной смерти в возрастных группах 20-29 лет и 30-39 лет является самоубийство (Fukada, 2012: Электронный ресурс).

Указанные сведения о самоубийствах от чрезмерной переработки в Японии представляют собой предельный случай и, хотя и подтверждают теоретические предположения, вряд ли могут рассматриваться как общемировая тенденция. Тем не менее остается несомненным тот факт, что переработка (не обязательно чрезмерная) негативно влияет на здоровье, качество личной и семейной жизни работающих по найму: не дает полноценно восстановиться, наладить отношения с детьми, мешает общению, сексуальной жизни, саморазвитию (Баланс работы ..., 2016; Ильин, 2011). Это приводит к неудовлетворенности, семейным конфликтам, порождает чувства бессилия, бесцельности, одиночества, вовлекая в негативную стрессовую ситуацию не только самого наемного работника, но и его окружение. Часть этих людей выбирают крайнюю форму выхода из психически-стрессового состояния - самоубийство (Государственная политика ..., 2007: 356), переводя его в разряд относительно массового, статистически устойчивого социального явления (Гилинский, 2011).

Вместе с тем уменьшение продолжительности рабочего времени ниже некоторого предела или полное отсутствие работы, следовательно, избыток внерабочего, прежде всего свободного, времени при наличии приемлемых социального статуса и дохода также вызывают неудовлетворенность и переживание дисбаланса жизненных сфер.

В самом деле, недостаток трудностей в удовлетворении естественных потребностей порождает отрицательные чувства пресыщения, скуки, потери вкуса к жизни, проявляющиеся в снижении актуальной мотивации повседневной жизни вплоть до полного отказа от приложения собственных усилий для достижения цели повседневной жизни, т. е. вплоть до самоубийства. Аанная логика согласуется с результатами физиологических экспериментов, в которых установлено, что длительное, стереотип- 
ное предъявление даже эмоционально значимых положительных раздражителей ведет к снижению мотивации достижения цели (Горбачева, 2010).

В то же время некоторые люди в данной ситуации пытаются искусственно поддерживать приемлемый уровень актуальной мотивации повседневной жизни путем создания (поиска) трудностей, зачастую уходя в раздичные формы девиантного, в том числе суицидального, поведения. В качестве ярких примеров уместно вспомнить о «золотой молодежи», «высшем обществе», «экстремалах», главной проблемой которых, как известно, является скука.

Кроме того, необходимо отметить, что трудовая активность играет важную роль в конституировании реальности повседневной жизни. Трудящееся «Я»выступает как целостное, нефрагментированное «Я», поскольку труд наиболее полно активизирует все потенциальные качества личности, наделяет их единством (Шюц, 1988). При снижении трудовой активности человек теряет чувство реальности, все больше погружаясь во внутренний мир, в котором нет характерного для повседневности долженствования, в связи с чем внимание к жизни ослабляется, а напряженно-бодрствующая установка заменяется созерцательной, воображающей (Минюшев, 2004: 31). В итоге происходит рассогласование внутренней и внешней жизни, выражающееся в утрате душевного равновесия и нежелании прилагать усилия для достижения цели повседневной жизни. Это может приводить к деперсонализации личности, опять же, повышающей риск суицида (Нуллер, 1981).

Указанные соображения позволяют рассматривать уровень распространенности самоубийств, по крайней мере среди работающих по найму, как социальный коррелят актуальной мотивации повседневной жизни, взятый с обратным знаком. Можно полагать, что в условиях относительно стабильной общественной ситуации снижение актуальной мотивации повседневной жизни работающих по найму с высокой вероятностью ведет к росту уровня распространенности самоубийств.

Вместе с тем самоубийство как статистически устойчивое социальное явление, распространенность которого подчиняется определенным закономерностям (Абрумова, Тихоненко, 1980), также служит индикатором социального, экономического, политического и психологического состояний социума (Гилинский, 2011; Говорин, Сахаров, 2008: 6; Юревич, 2016) и, безусловно, не может напрямую интерпретироваться как мера актуальной мотивации повседневной жизни.

\section{ТЕОРЕТИЧЕСКАЯ МОАЕАЬ ОЦЕНКИ}

\section{АКТУААЬНОЙ МОТИВАЦИИ ПОВСЕАНЕВНОЙ ЖИЗНИ}

Предлагаемая теоретическая модель оценки (измерения) актуальной мотивации повседневной жизни работающих по найму основывается на предположении о существовании немонотонной (квадратичной) зависимости актуальной мотивации повседневной жизни от трудности задачи, как это происходит на уровне индивида и малой группы в случае выполнения задачи с заданными стандартами деятельности (Gendolla, Wright, Richter, 2012; Richter, Gendolla, Wright, 2016: 151).

Теоретическая форма нелинейной (квадратичной) связи между әмпирическими признаками актуальной мотивации повседневной жизни и трудности задачи - уровнем распространенности самоубийств среди работающих по найму и средней продолжительностью рабочего времени - представлена на рисунке.

С ростом средней продолжительности рабочего времени (трудность задачи) уровень распространенности самоубийств среди работающих по найму снижается (акту- 


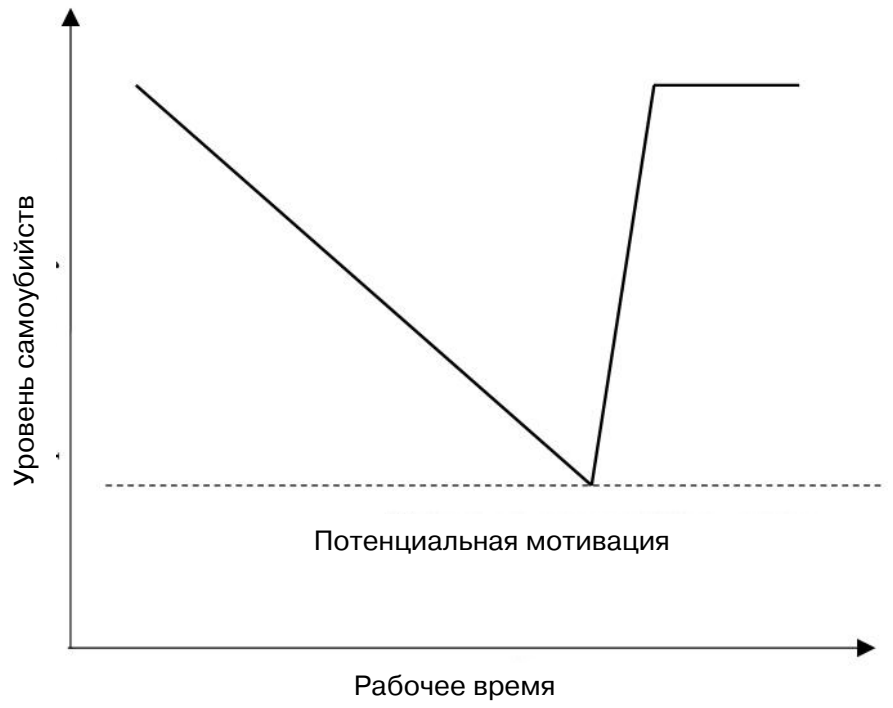

Зависимость уровня распространенности самоубийств среди работающих по найму от средней продолжительности рабочего времени.

Dependence of the level of prevalence of suicides on average duration of the working time

альная мотивация растет) до некоторого предела, соответствующего потенциальной мотивации (максимальной актуальной мотивации), за которым уровень самоубийств повышается (актуальная мотивация снижается).

Аля того чтобы уровень распространенности самоубийств среди работающих по найму, а точнее его изменение, характеризовал именно актуальную мотивацию повседневной жизни как квадратичную функцию трудности задачи, необходимо учесть (исключить) другие факторы (социальные, экономические, политические, философские, культурные, религиозные и др.), оставив для анализа только фактор «трудность задачи». Это возможно сделать, используя методологию панельных данных (Балаш В., Балаш О., 2002). Если значения факторов различны для разных стран, но постоянны во времени, их влияние можно учесть, включив в модель панельной регрессии индивидуальные эффекты для каждой страны.

Аля анализа связи уровня распространенности самоубийств среди работающих по найму и средней продолжительности рабочего времени предлагается использовать уравнение панельной квадратичной регрессии с фиксированными (индивидуальными) эффектами вида

$$
S_{i, t}=a_{i}+a_{1} T_{\mathrm{wi}, t}+a_{2} T_{\mathrm{w} i, t}^{2}+\varepsilon_{i, t}
$$

где $S_{i, t}$ - показатель уровня распространенности самоубийств среди работающих по найму в $i$-й капиталистической стране в период времени $t ; T_{\mathrm{w} i, t}-$ показатель средней продолжительности рабочего времени работающих по найму в $i$-й капиталистической стране в период времени $t ; a_{i}$ - индивидуальные эффекты для каждой $i$-й капиталистической страны, отражающие влияние постоянных во времени ненаблюдаемых переменных, характеризующих другие факторы актуальной мотивации; $a_{1}, a_{2}$ - коэффициенты панельной регрессии; $\varepsilon_{i, t}$ - остатки регрессии. 
Коэффициенты $a_{1}, a_{2}$ в панельной регрессии (1) являются количественными показателями связи и характеризуют среднее изменение уровня распространенности самоубийств среди работающих по найму $\left(S_{i, t}\right)$ при изменении средней продолжительности рабочего времени $\left(T_{w i, t}\right)$ и фиксированных индивидуальных эффектах, характеризующих другие факторы.

Пилотная апробация панельной регрессионной модели с фиксированными эффектами на данных выборки из 22 европейских стран за 1998-2012 гг. (Коротков, Загайнова, 2016b: Электронный ресурс), наиболее полно удовлетворяющих требованиям доступности, точности, представительности, релевантности, полноты и сопоставимости, позволила предварительно подтвердить гипотезу о существовании статистически значимой нелинейной (квадратичной) связи между уровнем распространенности самоубийств и средней продолжительностью рабочего времени, что при обратном переходе к исходным понятиям позволяет обоснованно предположить наличие квадратичной зависимости актуальной мотивации повседневной жизни работающих по найму от трудности задачи.

Предполагается, что дальнейший эконометрический анализ квадратичной связи между уровнем распространенности самоубийств и средней продолжительностью рабочего времени на основе концепции коинтеграции и модели с механизмом корректировки равновесия (Энгл, Грэнджер, 2015) применительно к панельным данным (Пелипась, Чубрик, 2007) позволит уточнить параметры этой связи, по значениям которых может быть найдена оптимальная средняя продолжительность рабочего времени как аргумент минимума квадратичной функции. При переходе к концептуальным терминам это будет означать оптимальную трудность задачи, при которой достигается максимальная актуальная мотивация повседневной жизни работающих по найму.

В свою очередь, наличие оптимального значения трудности задачи позволит перейти непосредственно к количественной оценке актуальной мотивации с использованием функции желательности и предложить измеритель (показатель) актуальной мотивации повседневной жизни работающих по найму, который может быть рассчитан по формуле

$$
M_{i, t}=\left(1-\frac{\left|T_{\text {wi,t }}-\grave{O}_{\text {woptimus }, t}\right|}{\max \left\{\left(T_{w \max , t}-\grave{O}_{\text {woptimus }, t}\right)\left(\grave{O}_{\text {woptimus }, t}-T_{\text {wmin }, t}\right)\right.},{ }^{\prime}\right.
$$

где $M_{i, t}$ - измеритель (показатель) актуальной мотивации повседневной жизни работающих по найму в $i$-й капиталистической стране в период времени $t$, баллов; $T_{\mathrm{w} i, t}$ показатель средней продолжительности рабочего времени работающих по найму в $i$-й капиталистической стране в период времени $t ; T_{\mathrm{w} \max , t}-$ максимальное значение показателя средней продолжительности рабочего времени работающих по найму среди всех изучаемых капиталистических стран в период времени $t ; T_{\mathrm{w} \min , t}-$ минимальное значение показателя средней продолжительности рабочего времени работающих по найму среди всех изучаемых капиталистических стран в период времени $t$; $T_{\text {woptimus,t }}$ - оптимальное значение показателя средней продолжительности рабочего времени работающих по найму среди всех изучаемых капиталистических стран в период времени $t ; N-$ максимальное количество баллов.

При этом $M_{i, t}=0$ баллов будет соответствовать минимальной актуальной мотивации повседневной жизни работающих по найму в $i$-й капиталистической стране среди всех изучаемых капиталистических стран в период времени $t$, а $M_{i, t}=N$ баллов - 
максимальной актуальной мотивации повседневной жизни работающих по найму в $i$-й капиталистической стране среди всех изучаемых капиталистических стран в период времени $t$. Величина актуальной мотивации $M_{i, t}$ тем ближе к $N$, чем меньше отклонение $T_{\text {wi,t }}$ от $T_{\text {woptimus, }}$.

\section{ЗАКАЮЧЕНИЕ}

В ходе проведенного теоретического исследования обоснована возможность интерпретации фактора актуальной мотивации повседневной жизни работающих по найму «трудность задачи» как средней продолжительности рабочего времени и использования уровня распространенности самоубийств, взятого с обратным знаком, в качестве социального коррелята актуальной мотивации. Это позволило перенести на уровень социальной группы (работающих по найму) известную квадратичную зависимость актуальной мотивации от трудности задачи, установленную на уровне индивида и малой группы в экспериментальных исследованиях, выполненных в русле теории интенсивности мотивации.

Выбор объекта исследования - работающих по найму в капиталистических странах - обусловлен, во-первых, удобством его изучения (объект позволяет корректную интерпретацию фактора трудности задачи при определенных допущениях); во-вторых, тем, что әто самая многочисленная группа (до 60\% населения) в капиталистическом типе общества, определяющая тенденции его развития.

Рассматривая актуальную мотивацию как квадратичную функцию трудности задачи, предлагается теоретическая модель оценки (измерения) актуальной мотивации повседневной жизни работающих по найму на основе панельной квадратичной регрессионной модели с фиксированными әффектами, позволяющей исключить другие факторы (социальные, экономические, политические, философские, культурные, религиозные и др.), оставив для анализа только фактор «трудность задачи», и функции желательности, позволяющей непосредственно получить балльные оценки актуальной мотивации.

Возможность существования связи между уровнем распространенности самоубийств и средней продолжительностью рабочего времени объективно подтверждается существованием явления «кароши» (смерть от переработки, включая самоубийство). Кроме того, дополнительным эмпирическим подтверждением выступают результаты пилотной апробации панельной квадратичной регрессионной модели с фиксированными эффектами на данных выборки из 22 европейских стран за 1998-2012 гг. (Коротков, Загайнова, 2016b: Электронный ресурс).

\section{СПИСОК АИТЕРАТУРЫ}

Абрумова, А. Г., Тихоненко, В. А. (1980) Аиагностика суицидального поведения. М. : ХОЗУ Миннефтепрома. 55 с.

Баланс работы и личной жизни у сотрудников российского производственного предприятия (2016) / А. Н. Моспан, Е. Н. Осин, Т. Ю. Иванова, Е. И. Рассказова, В. В. Бобров // Организационная психология. Т. 6. № 2. С. 8-29.

Балаш, В. А., Балаш, О. С. (2002) Модели линейной регрессии для панельных данных : учеб. пособие. М. : МЭСИ. 65 с.

В Японии женщина совершила самоубийство от... переработки? (2016) [Электронный ресурс]// Информационный портал новости в мире. URL: http://novostivmire.com/2016/10/18/vyaponii-zhenshhina-sovershila-samoubijstvo-ot-pererabotki/ (дата обращения: 01.12.2016). 
Гельман, А. (2015) Родителям доведенной на работе до самоубийства девушки выплатят 1 млн долларов [Электронный ресурс] // Metronews. 9 декабря. URL: http://www.metronews. $\mathrm{ru} /$ novosti/roditeljam-dovedjonnoj-na-rabote-do-samoubijstva-devushki-vyplatjat-1-mln-dollarov/Tpooli--Eg36f836SGxc/ (дата обращения: 01.12.2016).

Гилинский, Я. В. (2011) Самоубийство как социальный феномен // Социологический журнал. № 2. С. 39-48.

Говорин, Н. В., Сахаров, А. В. (2008) Суицидальное поведение: типология и факторная обусловленность. Чита : Изд-во «Иван Федоров». 178 с.

Горбачева, М. В. (2010) Сравнительный анализ психофизиологических показателей у детей и шимпанзе в процессе достижения цели : автореф. дис. ... канд. биол. наук. СПб. 20 с.

Государственная политика вывода России из демографического кризиса : монография (2007) / В. И. Якунин, С. С. Сулакшин, В. Э. Багдасарян и др. ; под общ. ред. С. С. Сулакшина. 2-е изд. М. : ЗАО Издательство "Экономика" ; Научный эксперт. 888 с.

Журавлев, А. А. (2009) Конкурентоспособность нации и образование: психологические аспекты [Электронный ресурс]// Информационный гуманитарный портал «Знание. Понимание. Умение». № 2. URL: http://www.zpu-journal.ru/e-zpu/2009/2/Zhuravlev/ (дата обращения: 01.12.2016).

Здравомыслов, А. Г., ЯАдв, В. А. (2003) Человек и его работа в СССР и после : учеб. пособие Аля вузов. 2 изд., испр. и доп. М. : Аспект Пресс. 485 с.

И. П. Павлов. Pro et contra (1999): Аичность и творчество И. П. Павлова в оценке современников и историков науки (к 150-летию со дня рождения) : антология / сост., биогр. очерк и примеч. Ю. П. Голикова, К. А. Аанге. СПб. : Издательство Русского Христианского гуманитарного института. $800 \mathrm{c.}$

Ильин, Е. П. (2011) Работа и личность. Трудоголизм, перфекционизм. СПб. : Питер. 65 с.

Инглхарт, Р., Вельцель, К. (2011) Модернизация, культурные изменения и демократия: Последовательность человеческого развития. М. : Новое издательство. 464 с.

Караханова, Т. М., Бессокирная, Г. П., Большакова, О. А. (2014) Труд и досуг рабочих (программа, инструментарий и некоторые предварительные результаты повторного исследования). М. : Институт социологии РАН. 162 с.

Караханова, Т. М., Бессокирная, Г. П., Большакова, О. А. (2015) Повседневная деятельность рабочих: труд, быт, досуг рабочих. М. : Институт социологии РАН. 100 с.

Коротков, П. А. (2014) Показатель напряжения коллективного рефлекса цели: теоретическая постановка // Психолого-социальная работа в современном обществе: проблемы и решения : Сб. мат. международной научно-практической конференции / под общ. ред. Ю. П. Платонова. СПб. : СПбГИПСР: Нестор-История. 448 с. С. 46-47.

Коротков, П. А., Загайнова, Е. А. (2015) Измерение мотивации в эмпирических исследованиях // Наука и современность. № 37 (1). С. 173-178.

Коротков, П. А., Загайнова, Е. А. (2016а) Актуальная мотивация повседневной жизни и трудность задачи: эмпирическая интерпретация на уровне социальной группы // Система ценностей современного общества. № 49. С. 90-94.

Коротков, П. А., Загайнова, Е. А. (2016b) Актуальная мотивация повседневной жизни работающих по найму и трудность задачи [Электронный ресурс] // Международный журнал прикладных и фундаментальных исследований. № 11-5. URL: http://www.applied-research.ru/ru/ article/view?id=10568 (дата обращения: 01.12.2016).

Кузнецова, Т. Г., Горбачева, М. В. (2012) Сравнительный анализ некоторых поведенческих реакций у детей и шимпанзе в процессе достижения ими цели с различной субъективной ценностью // Вестник Самарского университета. Естественно-научная серия. № 3. С. 192-202.

Кузнецова, Т. Г., Кузьмина, В. Е., Радченко, М. В. (2006) Функциональная организация поведенческих реакций у детей дошкольного возраста в сложных условиях достижения цели // Вестник Самарского университета. Естественно-научная серия. № 2 (42). С. 189-201. 
Иеонтьев, А. Н. (1959) Проблемы развития психики. М. : Изд. АПН РСФСР. 345 с.

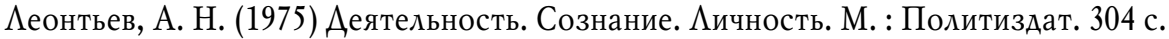

Минюшев, Ф. И. (2004) Социальная антропология : учеб. пособие для студентов высших учебных заведений. М. : Академический Проект. 288 с.

Нуллер, Ю. А. (1981) Аепрессия и деперсонализация. А. : Медицина. 207 с.

Павлов, И. П. (1973) Авадцатилетний опыт объективного изучения высшей нервной деятельности (поведения) животных. М. : Наука. 661 с.

Пелипась, И., Чубрик, А. (2007) Рыночные реформы и экономический рост в постсоциалистических странах: результаты эконометрического анализа // Эковест. №6 (1). C. 60-94.

Полякова, И. П. (2010) Специфика исследований повседневности // Вести высших учебных заведений Черноземья. № 3 (21). С. 86-89.

Президент японской корпорации взял на себя вину за самоубийство рядовой сотрудницы (2016) [Электронный ресурс] // BFM.RU. URL: https://www.bfm.ru/news/342811 (дата обращения: 01.12.2016).

Российская повседневность в условиях кризиса: взгляд социологов : аналитический доклад (2009) / науч. ред. Н. И. Покида. М. : Институт социологии РАН. 139 с.

Тищенко, М. (2016) Загнанные лошади. Почему в Японии тысячи людей буквально умирают от работы [Электронный ресурс]// Republic. 2 августа. URL: https://republic.ru/posts/71549 (дата обращения: 01.12.2016).

Факт дня. Почему в Японии тысячи людей умирают от переработки (2016) [Электронный ресурс]// Секрет фирмы. URL: http://secretmag.ru/news/2016/08/02/pochemu-v-yaponii-tysyachilyudej-umirayut-ot-pererabotki (дата обращения: 01.12.2016).

Хекхаузен, Х. (2003) Мотивация и деятельность. 2-е изд. СПб. : Питер; М. : Смысл. 860 с.

Шюц, А. (1988) Структура повседневного мышления // Социологические исследования. № 2. C. $129-137$.

Энгл, Р. Ф., Грэнджер, К. У. Аж. (2015) Коинтеграция и коррекция ошибок: представление, оценивание и тестирование // Прикладная эконометрика. № 39 (3). С. 107-135.

Юревич, А. В. (2016) Психологическое состояние современного российского общества как отражение его жизнеспособности // Жизнеспособность человека: индивидуальные, профессиональные и социальные аспекты / отв. ред. А. В. Махнач, А. Г. Аикая. М. : Изд-во «Институт психологии РАН». 755 с. С. $159-175$.

Brehm, J. W., Self, E. A. (1989) The intensity of motivation// Annual Review of Psychology. № 40. P. 109-131.

Elliot, A. J. (2006) The hierarchical model of approach-avoidance motivation // Motivation and Emotion. Vol. 30. Issue 2. P. 111-116. DOI: 10.1007/s11031-006-9028-7.

Fukada, Sh. (2012) Japan's Death March: Overworked Salarymen [Электронный ресурс] // Pulitzer Center. 13 июня. URL: http://pulitzercenter.org/reporting/japan-death-march-salarymanoverwork-stress-depression-karoshi-suicide (дата обращения: 01.12.2016).

Gendolla, G. H. E., Wright, R. A., Richter, M. (2012). Effort intensity: Some insights from the cardiovascular system // R. A. Ryan (Ed.), Oxford handbook of human motivation (pp. 420-438). New York: Oxford University Press. DOI: 10.1093/oxfordhb/9780195399820.013.0024

Gorvett, Z. (2016) "Death from overwork" is so common in Japan there's even a word for it. But is it physically possible? [Электронный ресурс] // BBC Capital. 13 сентября. URL: http://www. bbc.com/capital/story/20160912-is-there-such-thing-as-death-from-overwork (дата обращения: 01.12.2016).

Guest, D. (2002) Perspectives on the study of work-life balance // Social Science Information. № 41 (2). P. 255-279. DOI: 10.1177/0539018402041002005.

Richter, M., Gendolla, G. H. E., Wright, R. A. (2016) Three decades of research on motivational intensity theory: What we have learned about effort and what we still don't know // Advances in Motivation Science. № 3. P. 149-186. DOI: 10.1007/s11031-015-9536-4. 
Touré-Tillery, M., Fishbach, A. (2014) How to Measure Motivation: A Guide for the Experimental Social Psychologist // Social and Personality Psychology Compass. № 8/7. P. 328-341. DOI: 10.1111/ spc3.12110.

Аата поступления: 17.01.2017 2.

\author{
THEORETICAL APPROACH TO MEASURING \\ ACTUAL MOTIVATION OF A SOCIAL GROUP \\ P. A. KOROTKOV \\ Volga State University of TeCHNology
}

The article is devoted to the author's approach to measuring actual motivation of a social group's everyday life. This approach is oriented towards solving the task of the transfer of laboratory experiments' results onto big social groups. The interdisciplinary approach helps to specify the concepts of actual motivation in everyday life and the challenges of the task, which also involves the theory of motivational intensity, activity theory, analysis of the time budgets, work and life balance, and a comparative and physiological research of a functional organization of an integral behavioral act.

The selection of an average working time is justified as an indicator of the task difficulty with simultaneous specification of the subject of research. The subject of research is defined as employees in capitalist countries under conditions of a relatively stable social situation. The choice of research subjects is determined by the fact that employees are the most numerous group in the dominant society type which defines its tendencies of development. The switch to a national level is based on the effort to avoid an «ecological error» arising during the aggregation of individual-level data. The article also substantiates the possibility of using the reversed prevalence rate of suicides, as a social correlate of the actual motivation of the employees' everyday life.

A theoretical scoring model of an actual motivation of everyday life of employees has been developed on the basis of the analysis of a non-linear (quadratic) dependence of the prevalence rate of suicides on average duration of the working time with the use of a panel regression with fixed effects. This approach takes into account the dependence of variables of social and economic development and other unaccounted factors and leaves for analysis only the «task difficulty» factor.

Keywords: everyday life; employees; actual motivation; task difficulty; working time; suicide

\title{
REFERENCES
}

Abrumova, A. G. and Tihonenko, V. A. (1980) Diagnostika suicidal'nogo povedenija. Moscow, HOZU Minnefteproma. 55 p. (In Russ.).

Balans raboty i lichnoj zhizni u sotrudnikov rossijskogo proizvodstvennogo predprijatija (2016) / A. N. Mospan, E. N. Osin, T. Ju. Ivanova, E. I. Rasskazova, V. V. Bobrov. Organizacionnaja psibologija, vol. 6, no. 2, pp. 8-29. (In Russ.).

Balash, V. A. and Balash, O. S. (2002) Modeli linejnoj regressii dlja panel'nyb dannyb: workbook. Moscow, MESI. 65 p. (In Russ.).

V Japonii zhenshhina sovershila samoubijstvo ot ... pererabotki? (2016). Information portal "Novostivmire" [online] Available at: http://novostivmire.com/2016/10/18/v-yaponii-zhenshhinasovershila-samoubijstvo-ot-pererabotki/ (accessed: 01.12.2016). (In Russ.).

Gel'man, A. (2015) Roditeljam dovedjonnoj na rabote do samoubijstva devushki vyplatjat $1 \mathrm{mln}$ dollarov. Metronews. December 9 [online] Available at: http://www.metronews.ru/novosti/roditeljam-dovedjonnoj-na-rabote-do-samoubijstva-devushki-vyplatjat-1-mln-dollarov/Tpooli-Eg36f836SGxc/ (accessed: 01.12.2016). (In Russ.).

Gilinskij, Ja. V. (2011) Samoubijstvo kak social'nyj fenomen. Sociologicheskij zhurnal, no. 2, pp. 39-48. (In Russ.).

Govorin, N. V. and Saharov, A. V. (2008) Suicidal'noe povedenie: tipologija i faktornaja obuslovlennost'. Chita, "Ivan Fedorov" Publ. 178 p. (In Russ.). 
Gorbacheva, M. V. (2010) Sravnitel'nyj analiz psibofiziologicheskib pokazatelej u detej i sbimpanze $v$ processe dostizhenija celi: abstract of the diss. ... Candidate of Biology. St. Petersburg. 20 p. (In Russ.).

Gosudarstvennaja politika vyvoda Rossii iz demograficheskogo krizisa: monography (2007) / ed. by S. S. Sulakshin, 2 ed. Moscow, Economics Publ., Scientific expert. 888 p. (In Russ.).

Zhuravlev, A. L. (2009) Konkurentosposobnost' nacii i obrazovanie: psihologicheskie aspekty. Informational portal “Znanie. Ponimanie. Umenie”, no. 2 [online] Available at: http://www.zpujournal.ru/e-zpu/2009/2/Zhuravlev/ (accessed: 01.12.2016). (In Russ.).

Zdravomyslov, A. G. and Jadov, V. A. (2003) Chelovek $i$ ego rabota $v$ SSSR $i$ posle: work book, 2 augmented edition. Moscow, Aspectpress. 485 p. (In Russ.).

I. P. Pavlov. Pro et contra (1999): Lichnost' i tvorchestvo I. P. Pavlova v ocenke sovremennikov $i$ istorikov nauki ( $k$ 150-letiju so dnja rozbdenija): antologija / sost., biogr.ocherk i primech. Ju. P. Golikova, K. A. Lange. St. Petersburg, Izdatel'stvo Russkogo Hristianskogo gumanitarnogo instituta. 800 p.

Il'in, E. P. (2011) Rabota i lichnost'. Trudogolizm, perfekcionizm. SPb. : Piter. 65 p. (In Russ.).

Inglhart, R. and Vel'cel', K. (2011) Modernizacija, kul'turnye izmenenija i demokratija: Posledovatel' nost' chelovecheskogo razvitija. Moscow, New Publishing. 464 p. (In Russ.).

Karahanova, T. M., Bessokirnaja, G. P., Bol'shakova, O. A. (2014) Trud i dosug rabochib (programma, instrumentarij i nekotorye predvaritel'nye rezul' taty povtornogo issledovanija). Moscow, Institute of Sociology of the Russian Academy of Sciences (ISRAS). 162 p. (In Russ.).

Karahanova, T. M., Bessokirnaja, G. P., Bol'shakova, O. A. (2015) Povsednevnaja dejatel' nost' rabochib: trud, byt, dosug rabochib. Moscow, Institute of Sociology of the Russian Academy of Sciences (ISRAS). 100 p. (In Russ.).

Korotkov, P. A. (2014) Pokazatel' naprjazhenija kollektivnogo refleksa celi: teoreticheskaja postanovka. Psibologo-social' naja rabota $v$ sovremennom obshbestve: problemy i reshenija: Sb. mat. mezbdunarodnojnauchno-prakticheskojkonferencii/ ed. by. Ju. P. Platonova. St. Petersburg, SPbGIPSR, Nestor-Historia. 448 p. Pp. 46-47. (In Russ.).

Korotkov, P. A. and Zagajnova, E. A. (2015) Izmerenie motivacii v jempiricheskih issledovanijah. Nauka i sovremennost', no. 37 (1), pp. 173-178. (In Russ.).

Korotkov, P. A. and Zagajnova, E. A. (2016a) Aktual'naja motivacija povsednevnoj zhizni i trudnost' zadachi: jempiricheskaja interpretacija na urovne social'noj gruppy. Sistema cennostej sovremennogo obshbestva, no. 49, pp. 90-94. (In Russ.).

Korotkov, P. A. and Zagajnova, E. A. (2016b) Aktual'naja motivacija povsednevnoj zhizni rabotajushhih po najmu i trudnost' zadachi. Mezbdunarodnyj zburnal prikladnyb i fundamental' nyb issledovanij, no. 11-5, pp. 951-954 [online] Available at: http://www.applied-research.ru/ru/article/ view? $\mathrm{id}=10568$ (accessed: 01.12.2016). (In Russ.).

Kuznecova, T. G. and Gorbacheva, M. V. (2012) Sravnitel'nyj analiz nekotoryh povedencheskih reakcij u detej i shimpanze $\mathrm{v}$ processe dostizhenija imi celi s razlichnoj sub\#ektivnoj cennost'ju. Vestnik Samarskogo universiteta. Estestvennonauchnaja serija, no. 3, pp. 192-202. (In Russ.).

Kuznecova, T. G., Kuz'mina, V. E., Radchenko, M. V. (2006) Funkcional'naja organizacija povedencheskih reakcij u detej doshkol'nogo vozrasta v slozhnyh uslovijah dostizhenija celi. Vestnik Samarskogo universiteta. Estestvennonauchnaja serija, no. 2 (42), pp. 189-201. (In Russ.).

Leont'ev, A. N. (1959) Problemy razvitija psibiki. Moscow, APN RSFSR Publ. 345 p. (In Russ.).

Leont'ev, A. N. (1975) Dejatel' nost'. Soznanie. Lichnost'. Moscow, Politizdat. 304 p. (In Russ.).

Minjushev, F. I. (2004) Social'naja antropologija: workbook. Moscow, Akademicheskij Proekt. 288 p. (In Russ.).

Nuller, Ju. L. (1981) Depressija i depersonalizacija. Leningrad, Medicine. 207 p. (In Russ.).

Pavlov, I. P. (1973) Dvadcatiletnij opyt ob\#ektivnogo izuchenija vysshej nervnoj dejatel'nosti (povedenija) zhivotnyh. Moscow, Nauka Publ. 661 p. (In Russ.).

Pelipas', I. and Chubrik, A. (2007) Rynochnye reformy i jekonomicheskij rost v postsocialisticheskih stranah: rezul'taty jekonometricheskogo analiza. Jekovest, no. 6 (1). pp. 60-94. (In Russ.). 
Poljakova, I. P. (2010) Specifika issledovanij povsednevnosti. Vesti vysshib ucbebnyb zavedenij Chernozem' ja, no. 3 (21), pp. 86-89.

Prezident japonskoj korporacii vzjal na sebja vinu za samoubijstvo rjadovoj sotrudnicy (2016). BFM.RU [online] Available at: https://www.bfm.ru/news/342811 (accessed: 01.12.2016). (In Russ.).

Rossijskaja povsednevnost' v uslovijab krizisa: vzgljad sociologov: analytical report (2009)/ ed. by N. I. Pokida. Moscow, Institute of Sociology of the Russian Academy of Sciences. 139 p. (In Russ.).

Tishhenko, M. (2016) Zagnannye loshadi. Pochemu v Japonii tysjachi ljudej bukval'no umirajut ot raboty. Republic. August 2 [online] Available at: https://republic.ru/posts/71549 [archived in Web Cite] (accessed: 01.12.2016). (In Russ.).

Fakt dnja. Pochemu v Japonii tysjachi ljudej umirajut ot pererabotki (2016). Company's secret [online] Available at: http://secretmag.ru/news/2016/08/02/pochemu-v-yaponii-tysyachi-lyudejumirayut-ot-pererabotki (accessed: 01.12.2016). (In Russ.).

Shjuc, A. (1988) Struktura povsednevnogo myshlenija. Sociologicheskie issledovanija, no. 2, pp. 129-137. (In Russ.).

Jengl, Robert F. and Grjendzher, K. U. Dzh. (2015) Kointegracija i korrekcija oshibok: predstavlenie, ocenivanie i testirovanie. Applied Econometrics, no. 39 (3), pp. 107-135. (In Russ.).

Jurevich, A.V. (2016) Psihologicheskoe sostojanie sovremennogo rossijskogo obshhestva kak otrazhenie ego zhiznesposobnosti. Zhiznesposobnost' cheloveka: individual'nye, professional'nye $i$ social'nye aspekty / A. V. Mahnach and L. G. Dikaja (eds.). Moscow, Institute of Psychology of Russian Academy of Sciences, 755 p., pp. 159-175. (In Russ.).

Brehm, J. W. and Self, E. A. (1989) The intensity of motivation. Annual Review of Psychology, no. 40, pp. 109-131.

Elliot, A. J. (2006) The hierarchical model of approach-avoidance motivation. Motivation and Emotion, vol. 30, Issue 2, pp. 111-116. DOI: 10.1007/s11031-006-9028-7.

Fukada, Shiho (2012) Japan's Death March: Overworked Salarymen. Pulitzer Center. June 13 [online] Available at: http://pulitzercenter.org/reporting/japan-death-march-salaryman-overworkstress-depression-karoshi-suicide (accessed: 01.12.2016).

Gendolla, G. H. E., Wright, R. A., Richter, M. (2012) E?ort Intensity: Some Insights From the Cardiovascular System. The Oxford bandbook of buman motivation / In: R. A. Ryan (Ed.). New York, Oxford University Press, pp. 420-438. DOI: 10.1093/oxfordhb/9780195399820.013.0024.

Gorvett, Z. (2016). "Death from overwork" is so common in Japan there's even a word for it. But is it physically possible? // BBC Capital. URL: http://www.bbc.com/capital/story/20160912-isthere-such-thing-as-death-from-overwork [archived in WebCite] (accessed: 01.12.2016).

Guest, D. (2002) Perspectives on the study of work-life balance. Social Science Information, no. 41 (2). pp. 255-279. DOI: 10.1177/0539018402041002005.

Richter, M., Gendolla, G. H. E., Wright, R. A. (2016) Three decades of research on motivational intensity theory: What we have learned about effort and what we still don't know. Advances in Motivation Science, no. 3, pp. 149-186. DOI: 10.1007/s11031-015-9536-4.

Touré-Tillery, M. and Fishbach, A. (2014) How to Measure Motivation: A Guide for the Experimental Social Psychologist. Social and Personality Psychology Compass, no. 8/7, pp. 328-341. DOI: $10.1111 / \mathrm{spc} 3.12110$.

Submission date: 17.01.2017.

Коротков Петр Анатольевич - кандидат экономических наук, доцент кафедры транспортно-технологических машин Поволжского государственного технологического университета. Адрес: 424000, Россия, г. Йошкар-Ола, пл. Аенина, д. 3. Тел.: +7 (8362) 30-49-51, +7 (927) 871-65-97. Эл. aspec: korotkovpa@volgatech.net,korotp@bk.ru

Korotkov Peter Anatolievich, Candidate of Economics, Associate Professor, Department of Transport and Technological Machines, Volga State University of Technology. Postal address: 3, Lenin Sq., Yoshkar-Ola, Russian Federation 424000. Tel./ fax: +7 (8362) 30-49-51, +7 (927) 871-65-97. E-mail:korotkovpa@volgatech.net,korotp@bk.ru 